\title{
Probing of meteor showers at Mars during the encounter of comet C/2013 A1: predictions for the arrival of MAVEN/Mangalyaan
}

Syed A Haider ${ }^{1 *}$ and Bhavin M Pandya ${ }^{2}$

\begin{abstract}
We have estimated (1) production rates, (2) ion and electron densities of meteor ablation and (3) ionization for different masses and velocities of meteoroids when comet C/2013 A1 crossed the orbit of Mars on 19 October, 2014 at 18:27 UT. Meteor ablations of small masses $<10^{-4} \mathrm{~g}$ have created a broad layer between altitude $\sim 90 \mathrm{~km}$ and $110 \mathrm{~km}$. The meteoroids of large masses $\geq 10^{-4} \mathrm{~g}$ are burnt at around $60-90 \mathrm{~km}$ well below the main ionization peak at altitude $\sim 160 \mathrm{~km}$ produced in the nighttime by solar wind particle impact. The production rates and densities of 15 metallic ions $\mathrm{Mg}^{+}, \mathrm{Fe}^{+}, \mathrm{Si}^{+}, \mathrm{MgO}^{+}, \mathrm{FeO}^{+}, \mathrm{SiO}^{+}, \mathrm{MgCO}_{2}^{+}, \mathrm{MgO}_{2}^{+}, \mathrm{FeCO}_{2}^{+}, \mathrm{FeO}_{2}^{+}, \mathrm{SiCO}_{2}^{+}, \mathrm{SiO}_{2}^{+}, \mathrm{MgN}_{2}^{+}$, $\mathrm{FeN}_{2}^{+}$, and $\mathrm{SiN}_{2}^{+}$) have been computed self-consistently between altitudes $50 \mathrm{~km}$ and $150 \mathrm{~km}$. The twelve major peaks in the Ion Mass Spectra (IMS) are predicted by our model calculations. Our predicted ion and electron density profiles of metals provide benchmark values that can be observed by plasma probes onboard Mars Express (MEX), Mars Atmosphere and Volatile Evolution (MAVEN) and Mangalyaan.
\end{abstract}

\section{Introduction}

The comet C/2013 A1 was discovered on 3 January, 2013 at Siding Spring Observatory using Uppsala Southern Schmidt Telescope (http://ssd.jpl.nasa.gov/sbdb.cgi). It passed from the environment of Mars at minimum distance $\sim 134000 \mathrm{~km}$ (equal to $0.00059 \mathrm{AU}$ ) on 19 October, 2014 at nighttime [1]. The closest approach of this comet with Mars is shown in Figure 1. Mangalyaan and MAVEN have been explored into Mars environment on 5 and 18 November, 2013 respectively. Both missions reached in the orbit of Mars during last week of September, 2014. The Neutral Gas Ion Mass Spectrometer (NGIMS) onboard MAVEN has sampled the compositions of Mars atmosphere and observed eight metals (i.e. $\mathrm{Mg}, \mathrm{Fe}, \mathrm{Na}, \mathrm{K}$, $\mathrm{Mn}, \mathrm{Ni}, \mathrm{Cr}$ and $\mathrm{Zn}$ ) after the close encounter with $\mathrm{C} /$ 2013A1 (mars.nasa.gov./comets/siding spring). The Martian Exospheric Neutral Composition Analyzer (MENCA) onboard Mangalyaan should also measure the mass densities of cometary dust in the Martian environment (www.isro.org/mars/updates.aspx). Both missions do not carry radio occultation experiment. Therefore, they cannot

\footnotetext{
* Correspondence: haider@prl.res.in

${ }^{1}$ Space and Atmospheric Sciences, Physical Research Laboratory,

Navrangpura, Ahmedabad, India

Full list of author information is available at the end of the article
}

measure electron density profiles during this event. MEX is orbiting around Mars since April, 2004 (cf. [2]). It carries Mars Express radio science experiment (MaRS) which can observe electron density profiles in the atmosphere when the comet C/2013 A1 crossed the orbit of Mars. The Opportunity and Curiosity rovers landed on Mars on 25 January, 2004 and 6 August, 2013 respectively [3,4]. Their panoramic imaging cameras can also detect light of meteor bombardments in the environment of Mars during its encounter with this comet.

In this paper we have estimated production rates, ion and electron densities for meteor ionization of different masses and velocities of meteoroids at solar zenith angle (SZA) $110^{\circ}$. Our calculation suggests that two broad meteoric layers can be formed in the middle ionosphere during the encounter of the comet $\mathrm{C} / 2013 \mathrm{~A} 1$ with the atmosphere of Mars. It is found that the meteor ablation of small masses $<10^{-4} \mathrm{~g}$ would occur between altitude $90 \mathrm{~km}$ and $110 \mathrm{~km}$ where the free molecular path is several orders larger than the meteoroid size. This is known as micrometeoroids [5]. The meteoroids of large masses $\geq 10^{-4} \mathrm{~g}$ will penetrate deeper into the atmosphere and burn at altitude range $60-90 \mathrm{~km}$. The predicted rate of ion formation and ion/electron density of 


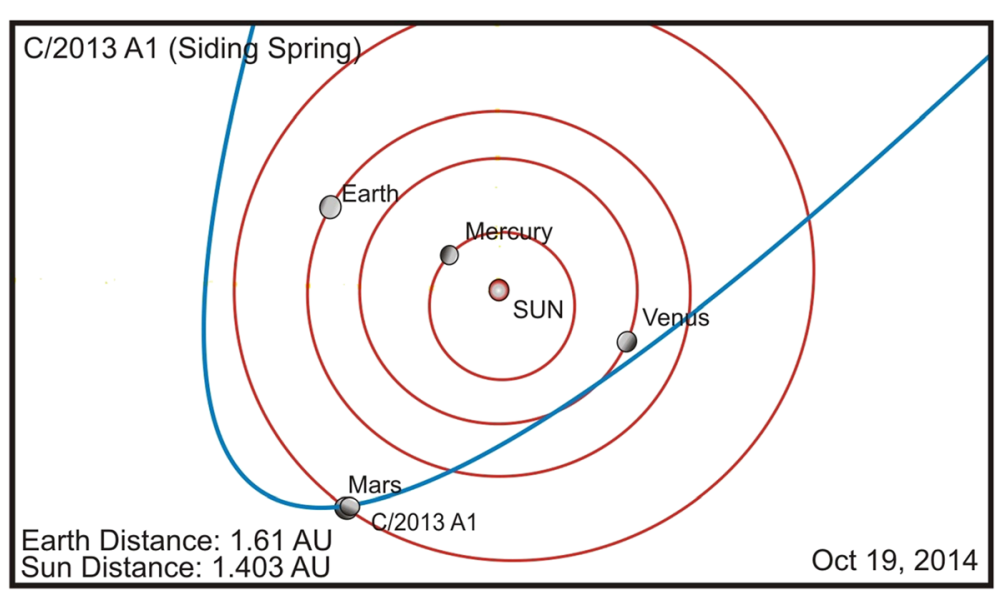

Figure 1 Comet C/2013 A1 is crossing Mars orbit from a solar distance 1.403 AU on October 19, 2014. Simulated view of comets and position of Sun, Earth, Mars, Mercury and Venus are shown in these figures (http://ssd.jpl.nasa.gov/sbdb.cgi).

meteors of all masses increases with velocities of meteoroids. During the meteor showers the ion and electron density are increased by several orders of magnitude in the middle ionosphere of Mars.

\section{Earlier measurements of meteoric layers on mars}

The presence of meteoric layers at about $80 \mathrm{~km}$ was first reported in the night time from the observations made by Mars 4 and Mars 5 [6]. Later a meteor observing campaign was carried out by Panoramic camera (Pancam) onboard Mars Exploration Rover (MER) Spirit which detected two Martian showers on 18 November and 27 October 2005 when comet Halley and 2001/R1 LONEOS intersected the orbit of Mars from a close distance $0.067 \mathrm{AU}$ and 0.001 AU, respectively. Domokos et al. [7] analyzed nighttime Pancam observations and estimated an upper limit of meteoroid flux $1.2 \times 10^{-19} \mathrm{~cm}^{-2} \mathrm{~s}^{-1}$ of mass larger than $4 \mathrm{~g}$. Molina-Cuberos et al. [8] used micro sized meteoroid fluxes $10^{-19}$ to $10^{-17} \mathrm{~cm}^{-2} \mathrm{~s}^{-1}$ for masses $\sim 10^{-4}$ to $10^{-10} \mathrm{~g}$ and calculated maximum electron density $\sim 2 \times 10^{4} \mathrm{~cm}^{-3}$ and $3 \times$ $10^{2} \mathrm{~cm}^{-3}$ during the daytime and nighttime ionosphere of Mars at altitudes $85 \mathrm{~km}$ and $83 \mathrm{~km}$ respectively.

Mars Global Surveyor (MGS) has observed 5600 electron density profiles from radio science experiment during the period 24 December 1998 to 9 June 2005 [9-11]. Withers et al. [10] found meteoric layers in 71 out of these 5600 electron density profiles. They have reported mean peak electron density $(1.33 \pm 0.5) \times 10^{4} \mathrm{~cm}^{-3}$ in the meteoric layer at a mean altitude of $91.7 \pm 4.8 \mathrm{~km}$. Their analysis suggests that the characteristics of these meteoric layers vary with season, SZA and latitude. Later Pandya and Haider [12] analyzed 1500 MGS electron density profiles to study the physical characteristics of meteoric plasma layers over Mars during the period January-June 2005. They found that 65 electron density profiles out of these 1500 profiles were strongly perturbed with peak densities $\sim(0.5-1.4) \times 10^{4} \mathrm{~cm}^{-3}$ at altitudes between $80 \mathrm{~km}$ and $105 \mathrm{~km}$, presumably due to ionization of meteoric atoms. Using these profiles they examined TEC in the lower ionosphere of Mars and found that maximum values of TEC occurred on 21 January and 23 May 2005, when comets 2007 PL42 and 4015 Wilson-Harrington intersected the orbit of Mars from close distances of 1.49 $\mathrm{AU}$ and $1.17 \mathrm{AU}$, respectively. The TEC values were increased by a factor of 5-7 on these days. Pandya and Haider [12] associated this significant increase with the meteor showers that were produced when Mars crossed the dust stream left along the orbits of these comets. These meteor showers were detected on Mars at different locations and at different times. The meteor shower of 21 January 2005 was observed at SZA = $74.3^{\circ}$, latitude $77.7^{\circ} \mathrm{N}$ and longitude $197.2^{\circ} \mathrm{E}$ during summer season $\left(\mathrm{Ls}=147.4^{\circ}\right)$. The meteor shower of 23 May 2005 was detected in the autumn season at Ls = $216.2^{\circ}, \mathrm{SZA}=84.9^{\circ}$, latitude $=65.1^{\circ} \mathrm{N}$ and longitude $20.2^{\circ} \mathrm{E}$.

Since 2004 MaRS experiment has observed 557 electron density profiles in the daytime and nighttime ionosphere of Mars [13,14]. Patzold et al. [13] observed meteoroid layers in $8 \%$ electron density profiles (i.e. 10 of 120 electron density profiles) of MEX measurements during the daytime ionosphere. Recently Haider et al. [15] have identified meteoric layers in two electron density profiles of MEX observations carried out in the nighttime ionosphere also, one on 22 August and the other on 25 September, 2005.

\section{Methods}

\section{Modeling and input parameters}

Recently MEX has observed three ionization peaks in the nighttime ionosphere of Mars at altitudes 80$100 \mathrm{~km}, 120 \mathrm{~km}$ and $160 \mathrm{~km}$, which were reproduced by model calculation due to impact of meteoroid, solar wind proton $(\leq 10 \mathrm{KeV})$ and electron $(\leq 1 \mathrm{KeV})$ 
respectively (cf. [15]). We have used this model to calculate the production rates and electron densities at SZA $110^{\circ}$ due to impact of micrometeoroids and meteoroids of different masses and velocities. These calculations are carried out between altitudes of $50 \mathrm{~km}$ and $150 \mathrm{~km}$ for meteor ablation that occurred on 19 October, 2014 during the encounter of comet/2013 A1 with Mars atmosphere. We have considered ablation of different meteoroids of masses $10^{-9} \leq \mathrm{m}<10^{1} \mathrm{~g}$ for fluxes $10^{-6} \leq \mathrm{f}<10$ ${ }^{-16} \mathrm{~cm}^{-2} \mathrm{~s}^{-1}$ at interval of $10 \mathrm{~g}$, where $\mathrm{m}$ and $\mathrm{f}$ are mass and flux of meteoroid particles respectively. The Figure 2 represents meteoroid spectrum obtained by measurements from Pioneers 8/11 HEOS and Pegasus satellites for large and small masses at 1.0 AU distance from the sun [16-18]. Grun et al. [19] have fitted this spectrum by interplanetary dust model. They have found that collision lifetime at 1.0 AU is small $\left(\sim 10^{4}\right.$ years $)$ for meteoroids of $10^{-4}$ to $1 \mathrm{~g}$ mass. For particles with masses $\mathrm{m} \leq 10^{-5} \mathrm{~g}$ the lifetimes were considerably larger than the collision lifetimes. Upper limit of meteoroid flux at Mars is observed to be $<10$ ${ }^{-15} \mathrm{~cm}^{-2} \mathrm{~s}^{-1}$ from Spirit/MER cameras for mass larger than $4 \mathrm{~g}$ [7]. This value of meteoroid flux is also shown in Figure 2. We have taken meteoroid fluxes from Figure 2 in our model calculation. Drolshagen [20] have calculated meteor impact velocity distribution between $10 \mathrm{~km} / \mathrm{s}$ to $30 \mathrm{~km} / \mathrm{s}$. Therefore, we have taken meteoroid velocities $10 \mathrm{~km} / \mathrm{s}, 18 \mathrm{~km} / \mathrm{s}$ and $30 \mathrm{~km} / \mathrm{s}$ and performed the calculation at five small and six large size particles of masses $10^{-5}$-to- $10^{-9} \mathrm{~g}$ and $10-$ to $-10^{-4} \mathrm{~g}$ respectively at $10 \mathrm{~g}$ interval. The large and small size particles are considered as meteoroids and micrometeoroids respectively. We have scaled meteoroid fluxes of Figure 2 to Martian orbit according to $\phi_{\mathrm{m}}=\phi_{\mathrm{e}} \times \mathrm{R}_{\mathrm{m}}^{-0.5}[21]$, where $\phi_{\mathrm{e}}$ and $\phi_{\mathrm{m}}$ are the particle fluxes of dust in the orbit of Earth and Mars respectively, $R_{m}$ is the distance of Mars from the sun in AU. The solar wind electron-protonhydrogen impact ionizations are not included in this model calculation because they are important above $120 \mathrm{~km}$ (cf. [15]).

Our chemical model depends on the temperature and density of the atmosphere. The nighttime temperature and density of gases $\mathrm{CO}_{2}, \mathrm{~N}_{2}, \mathrm{O}_{2}, \mathrm{O}$ and $\mathrm{CO}$ are calculated by Bougher et al. [22] between altitude $100 \mathrm{~km}$ and $220 \mathrm{~km}$ for the period September to October 2014. They solved 3D MTGCM (Mars Thermosphere General Circulation Model) to study the atmosphere of Mars at different local time, latitude, longitude and seasons. We have taken temperature and density from this model for 19 October, 2014 at altitude from $100 \mathrm{~km}$ to $150 \mathrm{~km}$. Between $50 \mathrm{~km}$ and $100 \mathrm{~km}$, the temperature and density of Haider et al. [15] are used after scaling them for 19 October, 2014. The equations of motion, ablation and energy are solved $[8,15]$ to calculate the ion production rates due to impact of meteoroids with different masses in the nighttime ionosphere of Mars. We have assumed cometary meteoroids which are composed of $61.7 \%$ oxygen, $24.2 \%$ silicon, $8.2 \%$ magnesium, and $5.9 \%$ iron in atoms of element to the total [23]. The ions $\mathrm{Fe}^{+}, \mathrm{Mg}^{+}$and $\mathrm{Si}^{+}$are produced due to meteor ablation in the nighttime ionosphere. The minimum velocities of $\mathrm{Fe}^{+}, \mathrm{Mg}^{+}$and $\mathrm{Si}^{+}$are taken 9.4, 11.1 and $11 \mathrm{~km} / \mathrm{s}$, respectively for the calculation of ionization probabilities. The rate coefficients of 57 chemical reactions given by Haider et al. [15] have been used to calculate electron density of metals. Using this chemical



Figure 2 Meteoroids fluxes observed by Pioneers 8 and 11, HEOS, and Pegasus satellites at 1.0 AU. These fluxes are scaled to Mars orbit at 1.5 AU. Plus (+) shows upper limit of meteoroid flux measured by Opportunity/MER rovers on Mars [7]. Solid line represents Interplanetary Dust Model of Grun et al. [19]. 
scheme we have predicted IMS and electron density in the nighttime ionosphere for different masses and velocities of meteoroids.

We have solved continuity coupled equations under steady state condition to predict IMS spectra. In this calculation transport of ions is neglected because transport time is several orders of magnitude higher than the chemical lifetime. In this model densities of each ion species, $\mathrm{n}_{\mathrm{i}}^{+}$, and electron, $\mathrm{n}_{\mathrm{e}}$, are calculated from the continuity equation and the charge neutrality condition using $P_{i}-l_{i} n_{i}^{+}=0$ and $n_{e}-\sum n_{i}^{+}=0$, where $P_{i}$ is the production rate by meteoroids/micrometeoroids and ion molecule reactions, and $l_{i}$ is the specific loss due to ion-molecule reactions and recombination with electrons. We have also investigated densities of metallic clusters due to termolecular associations of metallic ions with neutral molecules. It should be noted that direct meteoric ionization is the only ionization source considered here. The ionization by solar radiation or photoelectrons at the peak altitude of the meteoroid/micrometeoroid ablation is low and its influence on the

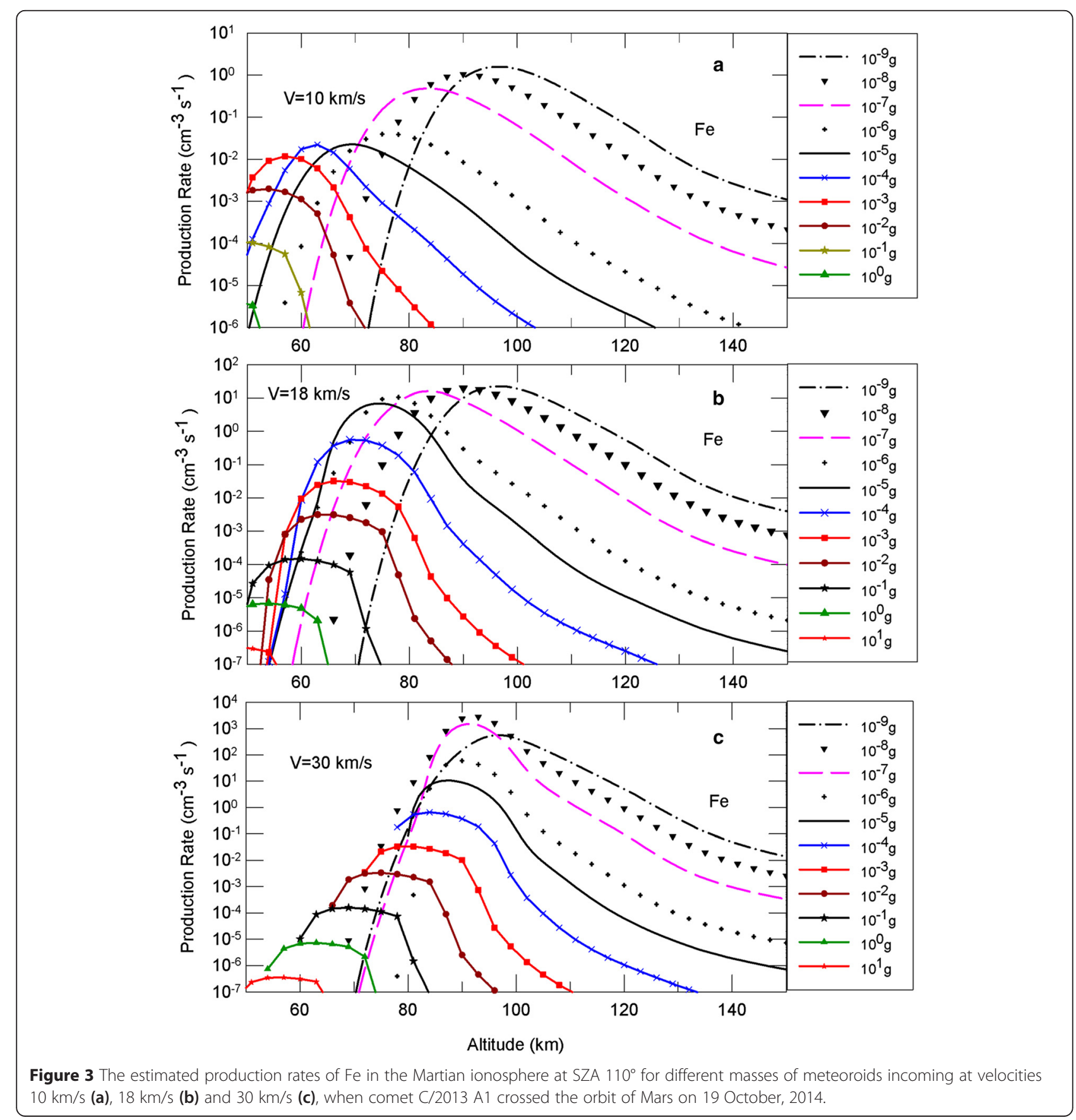


concentration of electrons and metallic ions is approximately negligible.

\section{Results and discussion}

In Figure 3a-c we have plotted production rates of $\mathrm{Fe}$ for different masses of meteoroids at velocities $10 \mathrm{~km} / \mathrm{s}$, $18 \mathrm{~km} / \mathrm{s}$ and $30 \mathrm{~km} / \mathrm{s}$ respectively. The production rates of $\mathrm{Mg}$ and $\mathrm{Si}$ are not plotted in Figure 3a-c because their values are similar to Fe. The productions of Fe are increasing with decreasing masses because meteoroid flux is inversely proportional to mass of the metals [19]. The meteoroids of large masses penetrate deep into the atmosphere and were burnt at altitude range $60-90 \mathrm{~km}$. The ablation of micrometeoroids takes place at altitude $\sim 90-110 \mathrm{~km}$ where the free molecular path is by several orders larger than the meteoroid size. The maximum and minimum production rates of Fe are estimated to be $10^{3} \mathrm{~cm}^{-3} \mathrm{~s}^{-1}$ and $5 \times 10^{-7} \mathrm{~cm}^{-3} \mathrm{~s}^{-1}$ due to impact velocity of $30 \mathrm{~km} / \mathrm{s}$. The production rates are decreasing with decreasing velocity of the particles because the flux
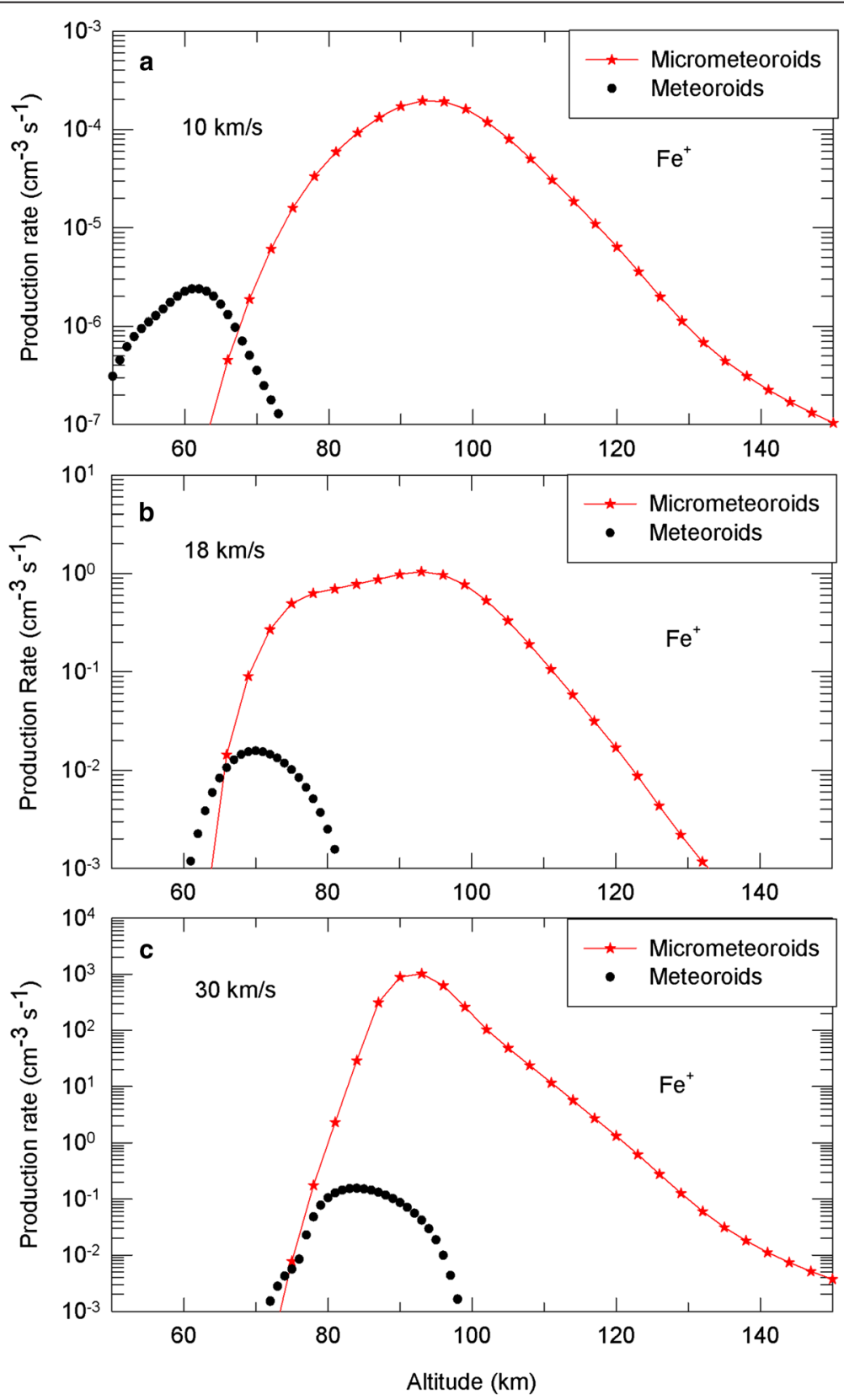

Figure 4 The estimated production rates of $\mathrm{Fe}^{+}$in the Martian ionosphere at SZA $110^{\circ}$ for micrometeoroids and meteoroids incoming at velocities $10 \mathrm{~km} / \mathrm{s}$ (a), $18 \mathrm{~km} / \mathrm{s}$ (b) and $30 \mathrm{~km} / \mathrm{s}$ (c), when comet C/2013 A1 crossed the orbit of Mars on 19 October, 2014. 
is decreasing with the velocity. Figure $4 \mathrm{a}-\mathrm{c}$ represent the ion production rates of $\mathrm{Fe}^{+}$due to ablation of micrometeoroids and meteoroids at velocities $10 \mathrm{~km} / \mathrm{s}, 18 \mathrm{~km} / \mathrm{s}$ and $30 \mathrm{~km} / \mathrm{s}$, integrated over masses $10^{-5}-10^{-9} \mathrm{~g}$ and $10-10^{-4} \mathrm{~g}$ respectively. The production of $\mathrm{Fe}^{+}$ions by micrometeoroids is $2-3$ orders of magnitude larger than the one due to meteoroids. We have estimated densities of 15 metallic ions $\mathrm{Mg}^{+}, \mathrm{Fe}^{+}, \mathrm{Si}^{+}, \mathrm{MgO}^{+}, \mathrm{MgCO}_{2}^{+}, \mathrm{MgO}_{2}^{+}$, $\mathrm{MgN}_{2}^{+}, \mathrm{FeO}^{+}, \mathrm{FeO}_{2}^{+}, \mathrm{FeN}_{2}^{+}, \mathrm{FeCO}_{2}^{+}, \mathrm{SiO}^{+}, \mathrm{SiCO}_{2}^{+}, \mathrm{SiN}_{2}^{+}$, and $\mathrm{SiO}_{2}^{+}$in the nighttime ionosphere of Mars. The electron density of meteoric layer is obtained from the sum of the densities of all metallic ions of micrometeoroids and meteoroids. In Figure 5a-c we have plotted electron densities due to ablation of meteoroids and micrometeoroids at velocities $10 \mathrm{~km} / \mathrm{s}, 18 \mathrm{~km} / \mathrm{s}$ and $30 \mathrm{~km} / \mathrm{s}$ respectively. The calculated peak heights and peak electron densities are compared in Table 1.

Recently, radio occultation experiment onboard MGS and MEX has observed meteoric plasma layers in the daytime and nighttime ionosphere of Mars at altitude range $80-100 \mathrm{~km}$ with peak electron density $\sim 10^{3}$ $10^{4} \mathrm{~cm}^{-3}$ [cf. [13-15]]. The density of meteoric layers
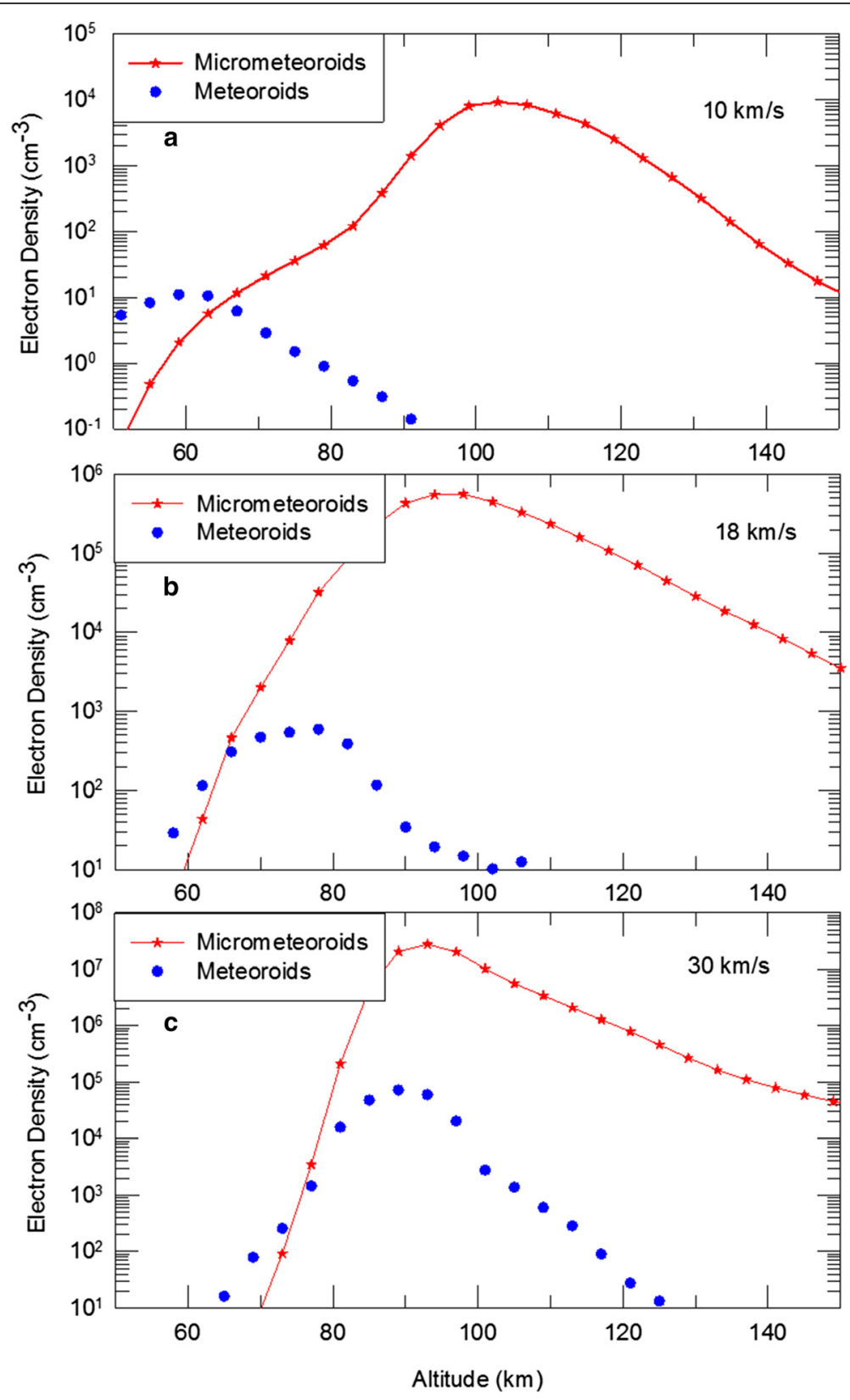

Figure 5 The predicted electron densities in the Martian ionosphere at SZA $110^{\circ}$ for micrometeoroids and meteoroids incoming at velocities $10 \mathrm{~km} / \mathrm{s}$ (a), $18 \mathrm{~km} / \mathrm{s}$ (b) and $30 \mathrm{~km} / \mathrm{s}$ (c), when comet C/2013 A1 crossed the orbit of Mars on 19 October, 2014. 
Table 1 Peak height and peak electron densities due to micrometeoroids and meteoroids ablation at different velocities

\begin{tabular}{|c|c|c|c|c|c|c|}
\hline \multirow[b]{2}{*}{ Source } & \multicolumn{2}{|c|}{ Velocity $10 \mathrm{~km} / \mathrm{s}$} & \multicolumn{2}{|c|}{ Velocity $18 \mathrm{~km} / \mathrm{s}$} & \multicolumn{2}{|c|}{ Velocity $30 \mathrm{~km} / \mathrm{s}$} \\
\hline & $\begin{array}{l}\text { Peak height } \\
(\mathrm{km})\end{array}$ & $\begin{array}{l}\text { Peak electron } \\
\text { density }\left(\mathrm{cm}^{-3}\right)\end{array}$ & $\begin{array}{l}\text { Peak height } \\
(\mathbf{k m})\end{array}$ & $\begin{array}{l}\text { Peak electron } \\
\text { density }\left(\mathrm{cm}^{-3}\right)\end{array}$ & $\begin{array}{l}\text { Peak height } \\
(\mathrm{km})\end{array}$ & $\begin{array}{l}\text { Peak electron } \\
\text { density }\left(\mathrm{cm}^{-3}\right)\end{array}$ \\
\hline Micrometeoroids & 105 & $\sim 1.0 \times 10^{4}$ & 95 & $\sim 3.5 \times 10^{5}$ & 90 & $\sim 3.0 \times 10^{7}$ \\
\hline Meteoroids & 60 & $\sim 1.0 \times 10^{1}$ & 75 & $\sim 6.0 \times 10^{2}$ & 90 & $\sim 5.0 \times 10^{4}$ \\
\hline
\end{tabular}
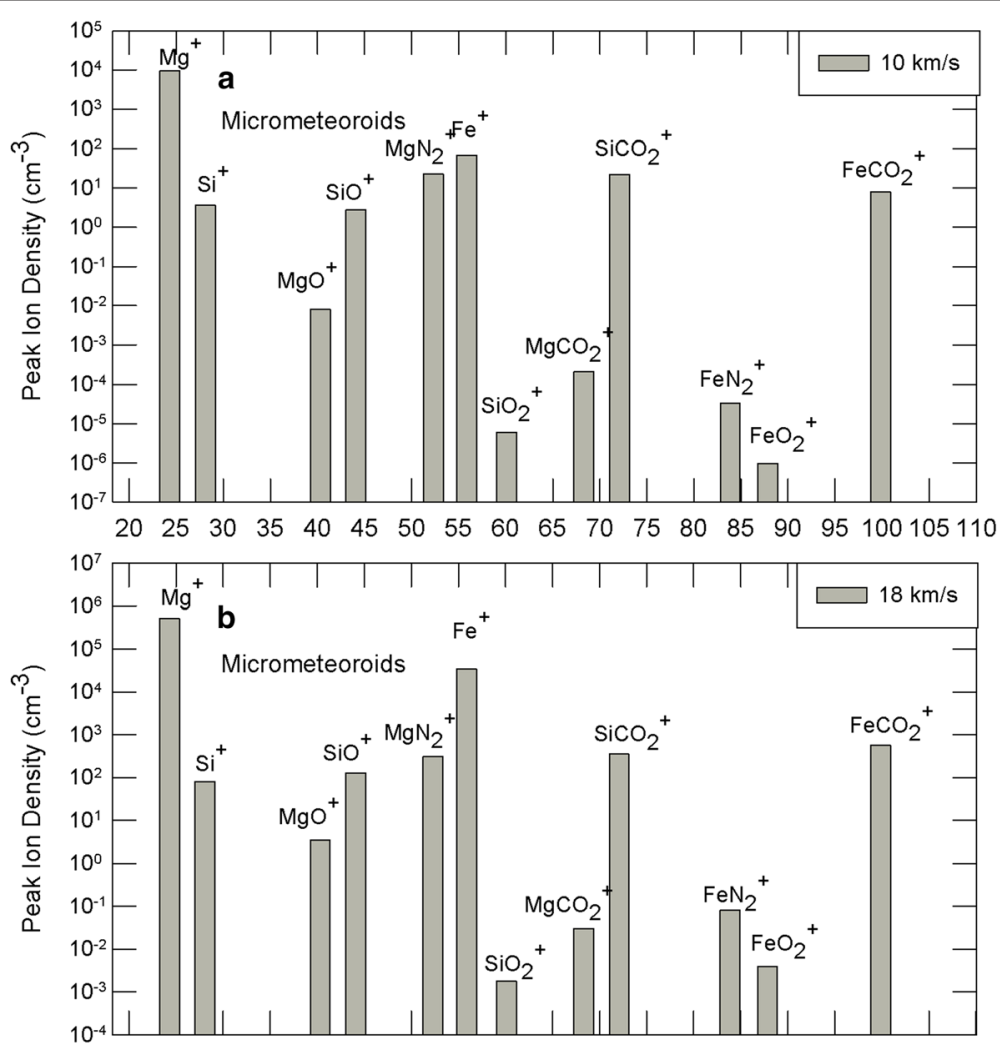

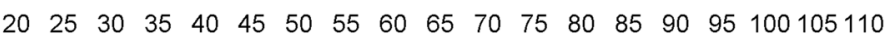

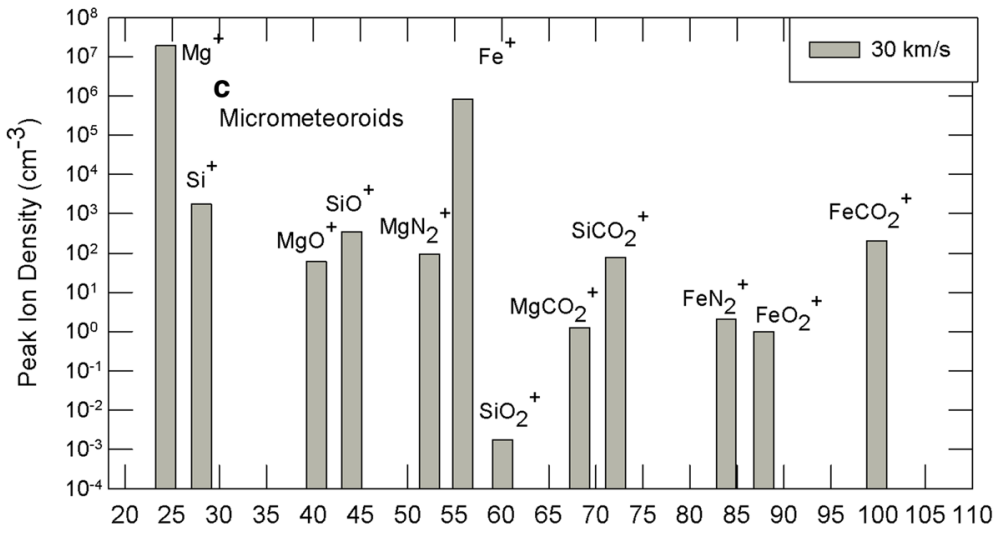

Atomic Mass (amu)

Figure 6 The predicted peak ion mass densities at SZA $110^{\circ}$ for micrometeoroids incoming at velocities $10 \mathrm{~km} / \mathrm{s}$ (a), $18 \mathrm{~km} / \mathrm{s}$ (b) and $30 \mathrm{~km} / \mathrm{s}$ (c), when comet C/2013 A1 crossed the orbit of Mars on 19 October, 2014. 
can change with the intensity of meteor showers. We report that the predicted peak electron densities due to incoming micrometeoroids of velocities $18 \mathrm{~km} / \mathrm{s}$ and $30 \mathrm{~km} / \mathrm{s}$ are larger than MGS/MEX measurements by $\sim 2-3$ orders of magnitude. This suggests that the intensity of proposed meteor showers would be significantly large on 19 October, 2014 due to ablation of micrometeoroids of high velocity. Thus, high speed micrometeoroids will produce bright showers in the atmosphere of Mars. The calculated peak electron densities for incoming meteoroids of velocities
$10 \mathrm{~km} / \mathrm{s}$ and $18 \mathrm{~km} / \mathrm{s}$ are lower than MGS/MEX measurements by $\sim 2-3$ orders of magnitude. The maximum electron densities predicted due to ablation of micrometeoroids and meteoroids of velocities $10 \mathrm{~km} / \mathrm{s}$ and $30 \mathrm{~km} / \mathrm{s}$ respectively are comparable in magnitude with these measurements.

Figures $6 \mathrm{a}-\mathrm{c}$ and $7 \mathrm{a}-\mathrm{c}$ represent the peak ion density spectra of fifteen masses between 24 and 100 amu due to ablation of micrometeoroids and meteoroids respectively at velocities $10 \mathrm{~km} / \mathrm{s}, 18 \mathrm{~km} / \mathrm{s}$ and $30 \mathrm{~km} / \mathrm{s}$. The
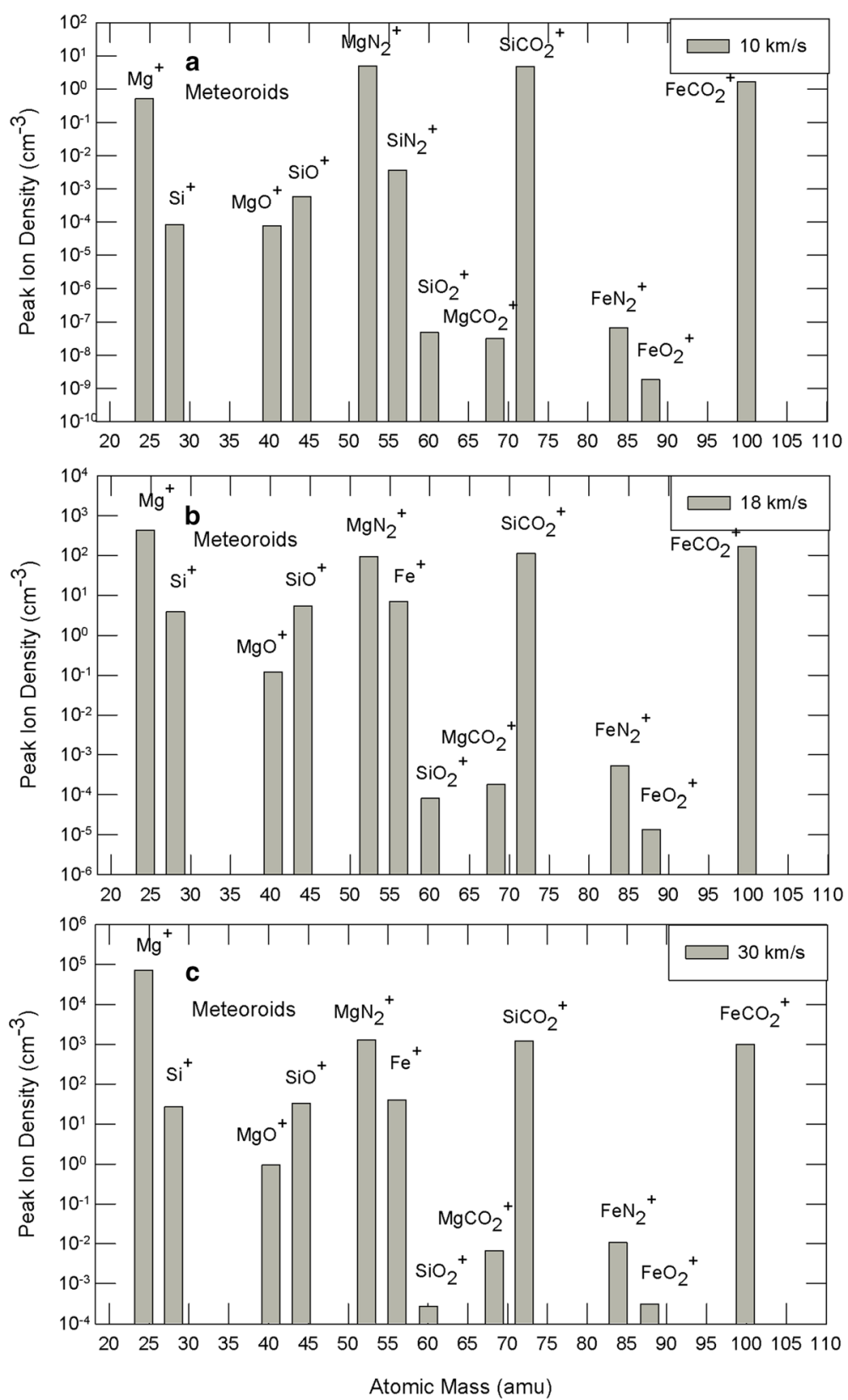

Figure 7 The predicted peak ion mass densities at SZA $110^{\circ}$ for meteoroids incoming at velocities $10 \mathrm{~km} / \mathrm{s}$ (a), $18 \mathrm{~km} / \mathrm{s}$ (b) and $30 \mathrm{~km} / \mathrm{s}$ (c), when comet C/2013 A1 crossed the orbit of Mars on 19 October, 2014. 
density of each ion strongly depends on the incoming velocities and the peak ion densities are increasing with the impact velocities of cometary meteoroids and micrometeoroids. The mass of ions $\mathrm{FeO}^{+}$and $\mathrm{MgO}_{2}^{+} / \mathrm{SiN}_{2}^{+}$are close to the masses of $\mathrm{SiCO}_{2}^{+}$and $\mathrm{Fe}^{+}$respectively. Therefore, the mass densities of $\mathrm{MgO}_{2}^{+}, \mathrm{SiN}_{2}^{+}$and $\mathrm{FeO}^{+}$ in IMS spectra cannot be separated. The mass densities of these ions are significantly lower than the mass densities of ions $\mathrm{SiCO}_{2}^{+}$and $\mathrm{Fe}^{+}$. The two most abundant ions $\mathrm{Mg}^{+}$and $\mathrm{Fe}^{+}$are produced due to micrometeoroids ablation at altitude $>90 \mathrm{~km}$. At height $<90 \mathrm{~km}$, twelve ions $\mathrm{Fe}^{+}, \mathrm{Mg}^{+}, \mathrm{Si}^{+}, \mathrm{MgO}^{+}, \mathrm{SiO}^{+}, \mathrm{MgN}_{2}^{+}, \mathrm{SiO}_{2}^{+}, \mathrm{MgCO}_{2}^{+}, \mathrm{FeO}^{+}$, $\mathrm{FeN}_{2}^{+}, \mathrm{FeO}_{2}^{+}$and $\mathrm{FeCO}_{2}^{+}$are produced due to meteoroids and micrometeoroids ablation.

Initially ions $\mathrm{Mg}^{+}, \mathrm{Fe}^{+}$and $\mathrm{Si}^{+}$are produced by direct meteoric ionization. The major cluster ions $\mathrm{FeCO}_{2}^{+}$and $\mathrm{SiCO}_{2}^{+}$are produced due to associations of $\mathrm{Fe}^{+}$and $\mathrm{Si}^{+}$ with $\mathrm{CO}_{2}$ by three body reactions. The other major cluster ion $\mathrm{MgN}_{2}^{+}$is also produced by three body reaction due to attachment of $\mathrm{Mg}^{+}$with $\mathrm{N}_{2}$. These cluster ions were lost by dissociative recombination reactions. The ions $\mathrm{FeCO}_{2}^{+}$and $\mathrm{SiCO}_{2}^{+}$are also produced from termolecular associations of $\mathrm{Fe}^{+}$and $\mathrm{Si}^{+}$with $\mathrm{CO}_{2}$ respectively at the rate coefficient $1.0 \times 10^{-30} \mathrm{~cm}^{6} \mathrm{~s}^{-1}$ [24]. The ions $\mathrm{MgCO}_{2}^{+}$, $\mathrm{MgO}_{2}^{+}$and $\mathrm{MgN}_{2}^{+}$are formed due to associations of $\mathrm{CO}_{2}, \mathrm{O}_{2}$, and $\mathrm{N}_{2}$ with $\mathrm{Mg}^{+}$at rate constants $1.0 \times 10^{-30}$, $9.0 \times 10^{-30}(200 / \mathrm{T})$ and $1.0 \times 10^{-30} \mathrm{~cm}^{6} \mathrm{~s}^{-1}$ respectively [25-27]. The dissociative recombination rate coefficients of clusters were estimated to be $\sim 10^{7} \mathrm{~cm}^{3} \mathrm{~s}^{-1}$ $[24,27,28]$, which is four orders of magnitude higher than the metallic ion recombination coefficient $\sim 10$ ${ }^{-12} \mathrm{~cm}^{3} \mathrm{~s}^{-1}$ [cf. $\left.[24,29]\right]$. The ions $\mathrm{FeO}^{+}, \mathrm{SiO}^{+}$and $\mathrm{MgO}^{+}$ are formed due to loss of $\mathrm{Fe}^{+}, \mathrm{Si}^{+}$and $\mathrm{Mg}^{+}$with $\mathrm{O}_{3}$ respectively. The densities of $\mathrm{FeO}^{+}, \mathrm{SiO}^{+}$and $\mathrm{MgO}^{+}$are lower than the densities of $\mathrm{FeCO}_{2}^{+}, \mathrm{SiCO}_{2}^{+}$and $\mathrm{MgCO}_{2}^{+}$ respectively because the densities of $\mathrm{O}_{3}$ is lower than $\mathrm{CO}_{2}$. In the meteoric layer of earth's ionosphere, termolecular reactions of metallic ions with oxygen followed by molecular dissociative recombination are very efficient processes. In the Mars atmosphere the concentration of oxygen is not high enough to decrease the concentration of metal ions through this reaction.

The ions $\mathrm{Fe}^{+}, \mathrm{Si}^{+}$and $\mathrm{Mg}^{+}$are also lost with $\mathrm{O}_{2}$ by three body reactions, which produce less $\mathrm{MgO}_{2}^{+}, \mathrm{FeO}_{2}^{+}$ and $\mathrm{SiO}_{2}^{+}$respectively because the density of $\mathrm{O}_{2}$ is lower than $\mathrm{CO}_{2}$. Table 2 shows possible ion species that contribute to different peaks in IMS spectra from 24 to $100 \mathrm{amu}$. First, second, third, fourth, and fifth peaks at 24, 28, 40, 44 and 52 amu are contributed by $\mathrm{Mg}^{+}, \mathrm{Si}^{+}$, $\mathrm{MgO}^{+}, \mathrm{SiO}^{+}$and $\mathrm{MgN}_{2}^{+}$respectively. The ions for sixth peak at 56 amu are responsible for $\mathrm{Fe}^{+}, \mathrm{SiN}_{2}^{+}$and $\mathrm{MgO}_{2}^{+}$. At this channel $\mathrm{Fe}^{+}$is the major ion in the vicinity of the ionization peak. The seventh and eighth peaks are produced due to ions $\mathrm{SiO}_{2}^{+}$and $\mathrm{MgCO}_{2}^{+}$at
Table 2 lon masses corresponding to $\leq 100$ amu

\begin{tabular}{ll}
\hline Mass & lons \\
\hline 24 & $\mathrm{Mg}^{+}$ \\
28 & $\mathrm{Si}^{+}$ \\
40 & $\mathrm{MgO}^{+}$ \\
44 & $\mathrm{SiO}^{+}$ \\
52 & $\mathrm{MgN}_{2}^{+}$ \\
56 & $\mathrm{Fe}^{+}, \mathrm{MgO}_{2}^{+}, \mathrm{SiN}_{2}^{+}$ \\
60 & $\mathrm{SiO}_{2}^{+}$ \\
68 & $\mathrm{MgCO}_{2}^{+}$ \\
72 & $\mathrm{FeO}^{+}, \mathrm{SiCO}_{2}^{+}$ \\
84 & $\mathrm{FeN}_{2}^{+}$ \\
88 & $\mathrm{FeO}_{2}^{+}$ \\
100 & $\mathrm{FeCO}_{2}^{+}$ \\
\hline
\end{tabular}

$60 \mathrm{amu}$ and $68 \mathrm{amu}$ respectively. The ninth peak at $72 \mathrm{amu}$ contains $\mathrm{FeO}^{+}$and $\mathrm{SiCO}_{2}^{+}$ions. The tenth, eleventh and twelve peaks are contributed by $\mathrm{FeN}_{2}^{+}$, $\mathrm{FeO}_{2}^{+}$and $\mathrm{FeCO}_{2}^{+}$at $84 \mathrm{amu}, 88 \mathrm{amu}$ and $100 \mathrm{amu}$ respectively.

Figures 8a-c and 9a-c represent the peak height spectra of fifteen ions between 24 and $100 \mathrm{amu}$ due to ablation of micrometeoroids and meteoroids of velocities $10 \mathrm{~km} / \mathrm{s}, 18 \mathrm{~km} / \mathrm{s}$ and $30 \mathrm{~km} / \mathrm{s}$ respectively. At altitudes between $60-70 \mathrm{~km}$ and $70-80 \mathrm{~km}$, the electron densities are mainly controlled by metallic ions $\mathrm{Fe}^{+}, \mathrm{Si}^{+}$and $\mathrm{Mg}^{+}$ due to impact of meteoroids of velocities $10 \mathrm{~km} / \mathrm{s}$ and $18 \mathrm{~km} / \mathrm{s}$ respectively. The major ion $\mathrm{Mg}^{+}$is calculated between altitude $80-90 \mathrm{~km}$ due to ablation of meteoroids of velocity $30 \mathrm{~km} / \mathrm{s}$. The most abundant ions $\mathrm{Fe}^{+}$ and $\mathrm{Mg}^{+}$are produced between altitudes 100 to $120 \mathrm{~km}$ due to ablation of micrometeoroids of velocity $10 \mathrm{~km} / \mathrm{s}$. The electron density between altitudes 90 to $100 \mathrm{~km}$ is produced from three major ions viz., $\mathrm{Mg}^{+}, \mathrm{Fe}^{+}$and $\mathrm{FeO}_{2}^{+}$ due to impact of micrometeoroids of velocity $18 \mathrm{~km} / \mathrm{s}$. The maximum densities of nine ions (viz., $\mathrm{Mg}^{+}, \mathrm{Si}^{+}, \mathrm{SiO}^{+}$, $\mathrm{Fe}^{+}, \mathrm{SiO}_{2}^{+}, \mathrm{MgCO}_{2}^{+}, \mathrm{FeO}^{+}, \mathrm{FeO}_{2}^{+}$and $\mathrm{FeCO}_{2}^{+}$) are calculated at altitude $\sim 90 \mathrm{~km}$ due to ablation of micrometeoroids of velocity $30 \mathrm{~km} / \mathrm{s}$.

\section{Uncertainty in the model}

Our model depends on the neutral density, temperature, meteoroid flux and various chemical reactions. The neutral density and temperature are taken from Bougher et al. [22] for 19 October, 2014, when comet C/2013 A1 crossed the orbit of Mars. The meteoroid fluxes are not measured in the orbit of Mars. We do not know how much meteoroid flux will precipitate in the Martian ionosphere during ablation on 19 October, 2014. We have taken meteoroid fluxes from the measurements made by Pioneers $8 / 11$ and Helios satellites in the orbit of earth with their experimental uncertainties of $15-20 \%$ [19]. 

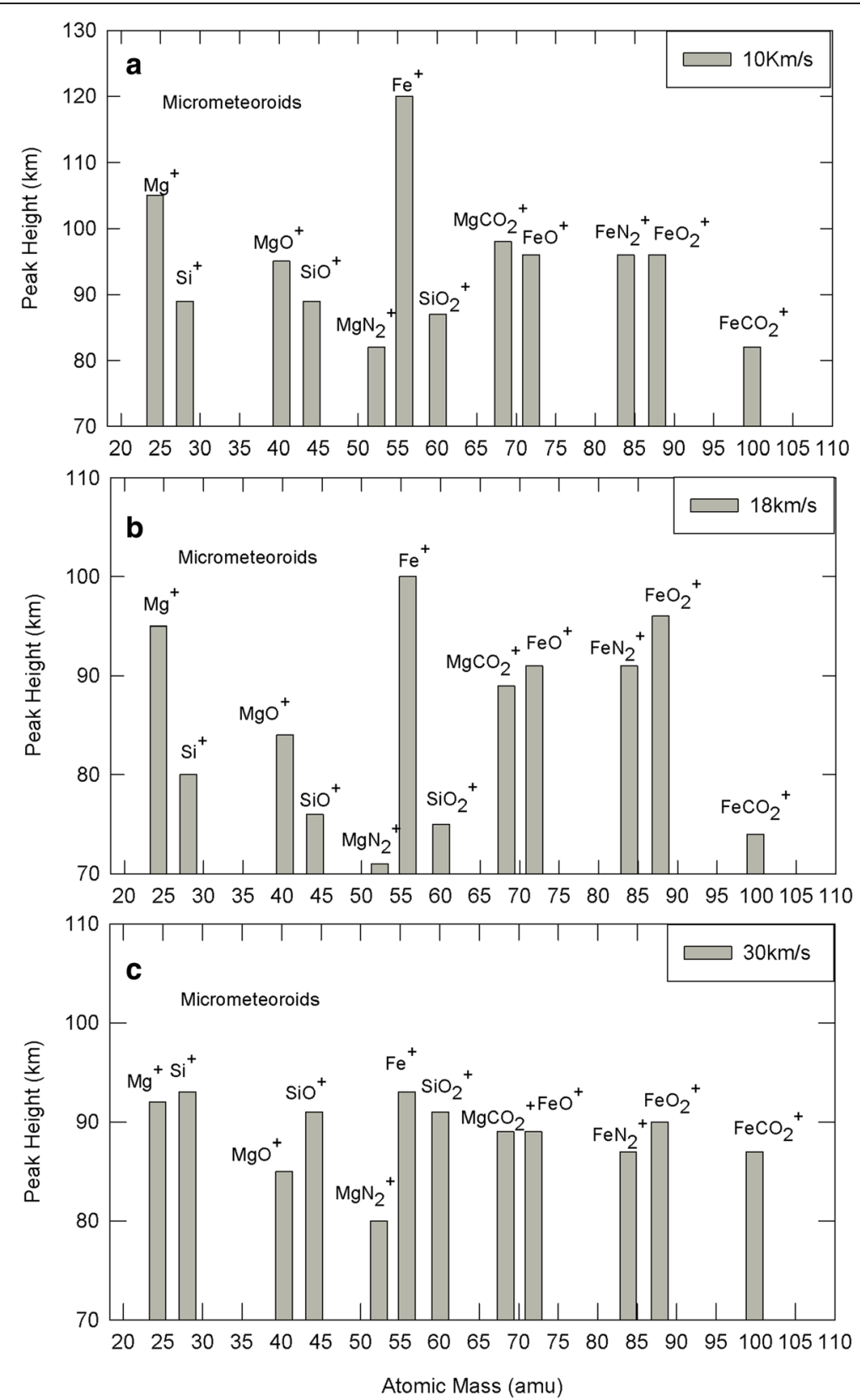

Figure 8 The predicted peak heights of metallic ion densities at SZA $110^{\circ}$ for micrometeoroids incoming at velocities $10 \mathrm{~km} / \mathrm{s}$ (a), $18 \mathrm{~km} / \mathrm{s}$ (b) and $30 \mathrm{~km} / \mathrm{s}$ (c), when comet C/2013 A1 crossed the orbit of Mars on 19 October, 2014.

These fluxes were scaled to Mars orbit. Some changes $5-8 \%$ are expected in the ion and electron density due to this uncertainty in the model. However, scaled spectra of meteoroids are in good agreement with the upper limit of meteoroid flux measured by MER cameras for mass larger than $4 \mathrm{~g}$ at Mars. The present chemical model is developed by a sequence of algebraic expressions, which obtains solutions after sufficient iterations for ion and electron density. Transport effect of ions and electrons are omitted in this model because this effect is appreciable above $200 \mathrm{~km}$ only. We note that above uncertainties are not very large.

\section{Constraints on the meteor measurements from MAVEN and mangalyaan}

Hubble Space Telescope observations indicated that the bulk of grains produced by comet C/2013 A1 will miss Mars. Only few percent of grains of higher velocities will reach Mars, peaking approximately 90-100 minutes after the close approach [30]. Later Tricarico et al. [31] 

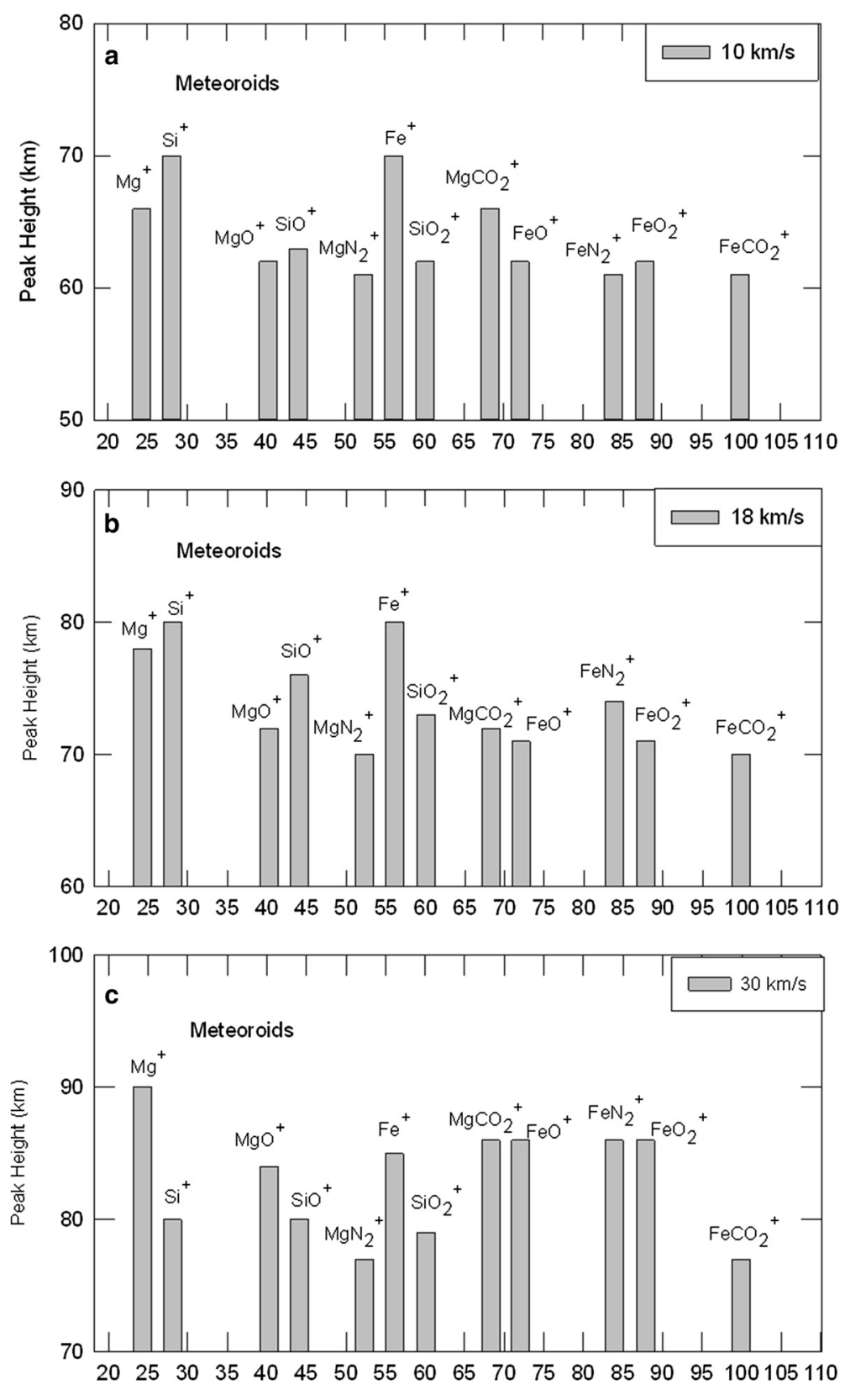

Atomic Mass (amu)

Figure 9 The predicted peak heights of metallic ion densities at SZA $110^{\circ}$ for meteoroids incoming at velocities $10 \mathrm{~km} / \mathrm{s}(\mathbf{a}), 18 \mathrm{~km} / \mathrm{s}$ (b) and $30 \mathrm{~km} / \mathrm{s}$ (c), when comet C/2013 A1 crossed the orbit of Mars on 19 October, 2014.

confirmed that younger grains of sub millimeter to several millimeters can reach Mars at higher velocities. Based on model results of Kelley et al. [32] MAVEN, MEX and Mangalyaan were impacted by large dust grains and Mars received as many as $\sim 10^{7}$ grains (100 kg of total dust). The radio occultation experiment onboard MGS and MEX have observed meteoric plasma layers in most of the electron density profiles during daytime and nighttime ionosphere of Mars [cf. [2,11,15]]. MGS has now stopped working since 2 November, 2006, but MEX is orbiting around Mars. However, MEX could not measure meteor electron density from this experiment on 19 October, 2014 during the encounters of comet C/2013 A1 with the atmosphere of Mars.

MAVEN and Mangalyaan are performing measurements from a highly elliptical orbit with a minimum height at about $150 \mathrm{~km}$ and $372 \mathrm{~km}$ respectively (www.isro.org/ mars/updates.aspx; www.nasa.gov/mission_pages/maven/ 
main/). These missions did not carry radio occultation experiment, which can measure complete electron density profiles above $50 \mathrm{~km}$. MAVEN carries Langmuir probe and ion/neutral mass spectrometer experiments. Mangalyaan also carries a mass spectrometer. Both experiments can measure plasma density in the upper atmosphere and exosphere of Mars. We have estimated meteoric ion and electron densities between altitude $50 \mathrm{~km}$ and $150 \mathrm{~km}$ for 19 October, 2014 due to intersection of comet C/2013 A1 with the atmosphere of Mars. The mass spectrometer onboard MAVEN is designed to measure ion concentrations as low as $0.1 \mathrm{~cm}^{-3}$ (www.nasa.gov/mission_pages/maven/main/). Using this instrument the meteor density is investigated for eight ions (i.e. $\mathrm{Mg}, \mathrm{Fe}, \mathrm{Na}, \mathrm{K}$, $\mathrm{Mn}, \mathrm{Ni}, \mathrm{Cr}$ and $\mathrm{Zn}$ ) between masses 24 and $100 \mathrm{amu}$. Mangalyaan also carries a high resolution color camera operating in the visible range $(0.4 \mu-0.7 \mu)$. This camera is measuring high quality visible images of Mars and its environments. The velocity of Mangalyaan at perigee $(\sim 372 \mathrm{~km})$ is about $4 \mathrm{~km} / \mathrm{s}$ where as it is less than $10 \mathrm{~m} / \mathrm{s}$ at apogee $(\sim 80000 \mathrm{~km})$ (www.isro.org/ mars/updates.aspx). Thus, this mission allows imaging of localized scenes at higher spatial resolution as well as provides a synoptic view of the full globe during its elliptical orbit. Therefore, the light of meteor bombardments during occurrence of meteor shower on 19 October, 2014 can be detected from this color camera. The analysis of this data is under progress.

\section{Conclusion}

We have predicted two broad meteoric layers in the nighttime ionosphere of Mars at altitude range 90$110 \mathrm{~km}$ and $60-90 \mathrm{~km}$ due to ablation of micrometeoroids and meteoroids respectively, when comet C/2013 A1 crossed the orbit of Mars on 19 October, 2014. The mass densities of 15 metallic ions are also predicted in the vicinity of ionization peaks. These ions are produced by direct meteoric ionization and lost by dissociative recombination. The production rates are calculated using the equations of motion, ablation, and energy. The ion mass densities are estimated by coupled continuity equations controlled by steady state condition. The magnitude of the meteoric layers depends on the concentration of metals and incoming velocities, viz., $10 \mathrm{~km} / \mathrm{s}, 18 \mathrm{~km} / \mathrm{s}$ and $30 \mathrm{~km} / \mathrm{s}$ of meteoroids and micrometeoroids, We have obtained that the concentrations of ions and electron strongly depend on the variations of the incoming velocities. It is also found that ion and electron densities can be increased by several orders of magnitude in the middle ionosphere of Mars during the meteor showers. Our estimated results can be confirmed in future by plasma probes onboard MAVEN and Mangalyaan.

\section{Competing interests}

The authors declare that they have no competing interest. We are exempt from paying article processing charges. We do not hold stock or shares in any organizations that may gain or lose financially from publication of this manuscript. We are not applying for any patents. There are no financial competing interests.

\section{Authors' contributions}

SAH has proposed the idea of meteoroid and micrometeoroid ablations on Mars. He has drafted, interpreted and analyzed the model results to prepare this manuscript. He has also presented this paper in AOGS 2014 meeting held in Sapporo, Japan. BMP has developed a model calculation of ion and electron densities caused by meteoroid/micrometeoroid ablations at different impact velocities in the atmosphere when comet $\mathrm{C} / 2013 \mathrm{~A} 1$ will interact with Mars. Both authors read and approved the final manuscript.

\section{Acknowledgement}

Authors are thankful to MAVEN and Mangalyaan team for the discussion on Mars-comet tail intersection on 19 October, 2014 when meteor shower events can be detected by these missions. We also thank S.W. Bougher (email: bougher@umich.edu) for providing us density and temperature data obtained from Mars Thermosphere General Circulation Model (MTGCM) of Mars atmosphere for the month of October, 2014.

\section{Author details}

${ }^{1}$ Space and Atmospheric Sciences, Physical Research Laboratory, Navrangpura, Ahmedabad, India. ${ }^{2}$ Permanent Address: Physics Department, C.U. Shah College, Ahmedabad, India.

Received: 24 September 2014 Accepted: 17 April 2015

Published online: 17 June 2015

\section{References}

1. Farnocchia D, Chesley SR, Chodas PW, Tricarico P, Kelley MSP, Famham TL (2014) Trajectory analysis for the nucleus and dust of comets C/2013 A1 (Siding Spring). Astrophys J 790:114

2. Haider SA, Mahajan KK, Kallio E (2011) Mars ionosphere: A review of experimental results and modeling studies. Rev Geophys 49:37, doi: 10.1029/2011RG000357

3. Arvidson RE, Ashley JW, Bell JF III, Chojnacki M, Cohen J, Economou TE, Farrand WH, Fergason R, Fleischer I, Geissler P, Gellert R, Golombek MP, Grotzinger JP, Guinness EA, Haberle RM, Herkenhoff KE, Herman JA, lagnemma KD, Jolliff BL, Johnson JR, Klingelhöfer G, Knoll AH, Knudson AT, Li R, McLennan SM, Mittlefehldt DW, Morris RV, Parker TJ, Rice MS, Schröder $C$ et al (2011) Opportunity Mars rover mission: Overview and selected results from Purgatory ripple to traverses to Endeavour crater. J Geophys Res 116:E00F15, Doi: 10.1029/2010JE003746

4. Mahaffy PR, Webster CR, Atreya SK, Franz H, Wong M, Conrad PG, Harpold D, Jones JJ, Leshin LA, Manning H, Owen T, Pepin RO, Squyres S, Trainer M, MSL Scinence Team (2013) Abundance and isotopic composition of gases in the Martian atmosphere from the Curiosity Rover. Science $341(6143)$ : 236-266, doi: 10.1126/science1237966

5. Love SG, Brownlee DE (1993) A direct measurement of the terrestrial mass accretion rate of cosmic dust. Science 262(5133):550-553

6. Savich NA, Samovol VA (1976) The nighttime ionosphere of Mars from Mars 4 and Mars 5 dual frequency radio occultation measurements. Space res XV:1009-1010

7. Domokos A, Bell JF, Brown P, Lemmon MT, Suggs R, Vaubaillon J, Cook W (2007) Measurement of the meteoroid flux at Mars. Icarus 191:141-150

8. Molina-Cuberos GJ, Wittasse O, Lebreton J-P, Rodrigo R, Lopez-Moreno JJ (2003) Meteoric ions in the atmosphere of Mars. Planet Space Sci 51:239-249

9. Withers P, Mendillo M (2005) Response of peak electron densities in the Martian ionosphere to day-to-day changes in solar flux due to solar rotation. Planet and Space Sci 53:1401-1418

10. Withers P, Mendillo M, Hinson DP, Cahoy K (2008) Physical characteristics and occurrence rates of meteoric plasma layers detected in the Martian ionosphere by Mars Global Surveyor Radio Science Experiment. J Geophys Res 113:A12314, doi: 10.1029/2008JA013636

11. Haider, S.A., and K.K. Mahajan (2014), Lower and upper ionosphere of Mars, Space Sci. Rev. Doi:10.1007/s11214-014-0058.2. 
12. Pandya BM, Haider SA (2012) Meteor impact perturbation in the lower ionosphere of Mars: MGS observations. Planet Space Scie 63/64:105-109, 837-839, doi:10.1126/science 1117755

13. Patzold M, Tellmann S, Hausler B, Hinson D, Schaa R, Tyler GL (2005) A sporaidic third layer in the ionosphere of Mars. Science 310:837-839, doi: 10.1126/science 1117755

14. Withers P, Fillingim MO, Lillis RJ, Hausler B, Hinson DP, Tyler GL, Patzold M, Peter K, Tellmann S, Witasse O (2012) Observations of the nightside ionosphere of Mars by Mars Express Radio Science Experiment (MaRs). J Geophys Res 117:A12307, doi: 10.1029/2012JA018185

15. Haider SA, Pandya BM, Molina-Cuberos GJ (2013) Nighttime ionosphere caused by meteoroid ablation and solar wind electron-proton-hydrogen impact on Mars: MEX observation and modeling. J Geophys Res 118:1-9, doi: 10.1002/jgra.50590

16. Berg OE, Gerloff U (1971) More than two years of micrometeorite data from two Pioneer satellites. Space Res 11:225-235

17. Hoffmann H-J, Fechtig H, Grun E, Kissel J (1975) First results of the micrometeoroid experiment S215 on HEOS 2 satellite. Planet Space Sci 23:215-224

18. Naumann RJ, DW Jex, CL Johnson (1969) Calibration of Pegasus and Explorer XXIII detector pannels. NASA Tech Rep. TR R-321

19. Grun E, Zook HA, Fechtig H, Giese RH (1985) Collisional balance of the meteoritic complex. Icarus 62:244-272

20. Drolshagen G, (2009) Comparison of Meteoroid Models. IADC Al 24.1, Final Report Issue: final; 05-Nov-2009

21. Bauer SJ (1973) Physics of Planetary lonospheres. Springer, New York

22. Bougher SW, McDunn TM, Zoldak KA, Forbes JM (2009) Solar cycle variability of Mars dayside exospheric temperatures; Model evaluation of underlying thermal balance. Geophys Res Lett 36:L05201, doi: 10.1029/2008GL036376

23. Jones W (1997) Theoretical and observational determinations of the ionization coefficient of meteors. Mon Not R Astron Soc 288:995-1003

24. Helmer H, Plane JMC, Qian J, Gardner CS (1998) A model of meteoric iron in the upper atmosphere. J Geophys Res 103:10913-10925

25. Whalley CL, Plane MC (2010) Meteoric ion layers in the Martian 533 atmosphere. Faraday Discuss 147:349-368. doi:10.1039/c003726E

26. Whalley CL, Martin JCG, Wright TG, Plane MC (2011) A kinetic 535 study of $\mathrm{Mg}+$ and $\mathrm{Mg}$ containing ions reacting with $\mathrm{O} 3, \mathrm{O} 2, \mathrm{~N} 2, \mathrm{CO} 2, \mathrm{~N} 2 \mathrm{O}$ and 536 H2O: Implications for magnesium ion chemistry in the upper atmosphere. Phys 537 Chem Chem Phys 13:6352-6364. doi:10.1039/c0cp02637a

27. McNeil WJ, Lai ST, Murad E (1996) A model for meteoric Magnesium in the ionosphere. J Geophys Res 101(A3):5251-5259

28. Pesnell WD, Grebowsky JM (2000) Meteoric magnesium in the Martian atmosphere. J Geophys Res 105:1695-1703

29. Pequignot D, Aldrovandi SMV (1986) The ionization balance in HI regions. Astron Astrophys 161:169-176

30. Moorhead A, Wiegert PA, Blaauw R, Cook WJ (2014) The meteoroid fluence at Mars due to comet C/2013 A1 (Siding Spring). Icarus 231:13-21

31. Tricarico P, Samarasinha NH, Sykes M, Li J-Y, Famham TL, Kelley MSP (2014) Delivery of dust grains from comet C/2013 A1 (Siding Spring) to Mars. Astrophys J Lett 787:L35, doi: 10.1088/2041-8205/787/2/L35

32. Kelley SPM, Farnham TL, Bodewits D (2014) A study of dust and gas at Mars from comet C/2013 A1 (Siding Spring). Astrophys J Lett 792:L16, doi: 10.1088/2041-8205/792/1/L16

\section{Submit your manuscript to a SpringerOpen ${ }^{\odot}$ journal and benefit from:}

- Convenient online submission

- Rigorous peer review

- Immediate publication on acceptance

- Open access: articles freely available online

- High visibility within the field

- Retaining the copyright to your article 